\title{
Erratum to: Observations of entomophagy across Benin - practices and potentials
}

\author{
L. G. Riggi $^{1}$ - M. Veronesi ${ }^{2}$ - G. Goergen ${ }^{3}$. \\ C. MacFarlane ${ }^{4}$. R. L. Verspoor ${ }^{5}$
}

Published online: 6 February 2016

(C) Springer Science+Business Media Dordrecht and International Society for Plant Pathology 2016

Erratum to: Food Sec.

DOI:10.1007/s12571-015-0509-y

Unfortunately a mistake was made in the name of a genus mentioned in Table 2. It should read Sternocera castanea and not Strapsis castanea.

New information was also added to Table 2. The succeeding page shows the correct versions of Table 2 .

The online version of the original article can be found at http://dx.doi.org/ 10.1007/s12571-015-0509-y.

\section{G. Riggi}

laura.riggi@slu.se

1 Department of Ecology, Swedish University of Agricultural Sciences (SLU), 75007 Uppsala, Sweden

2 Building and Social Housing Foundation (BSHF), Coalville, UK

3 International Institute of Tropical Agriculture, Biodiversity Centre, Cotonou, Benin

4 Bugs for Life, Edinburgh, UK

5 Institute of Integrative Biology, University of Liverpool, Liverpool, UK 


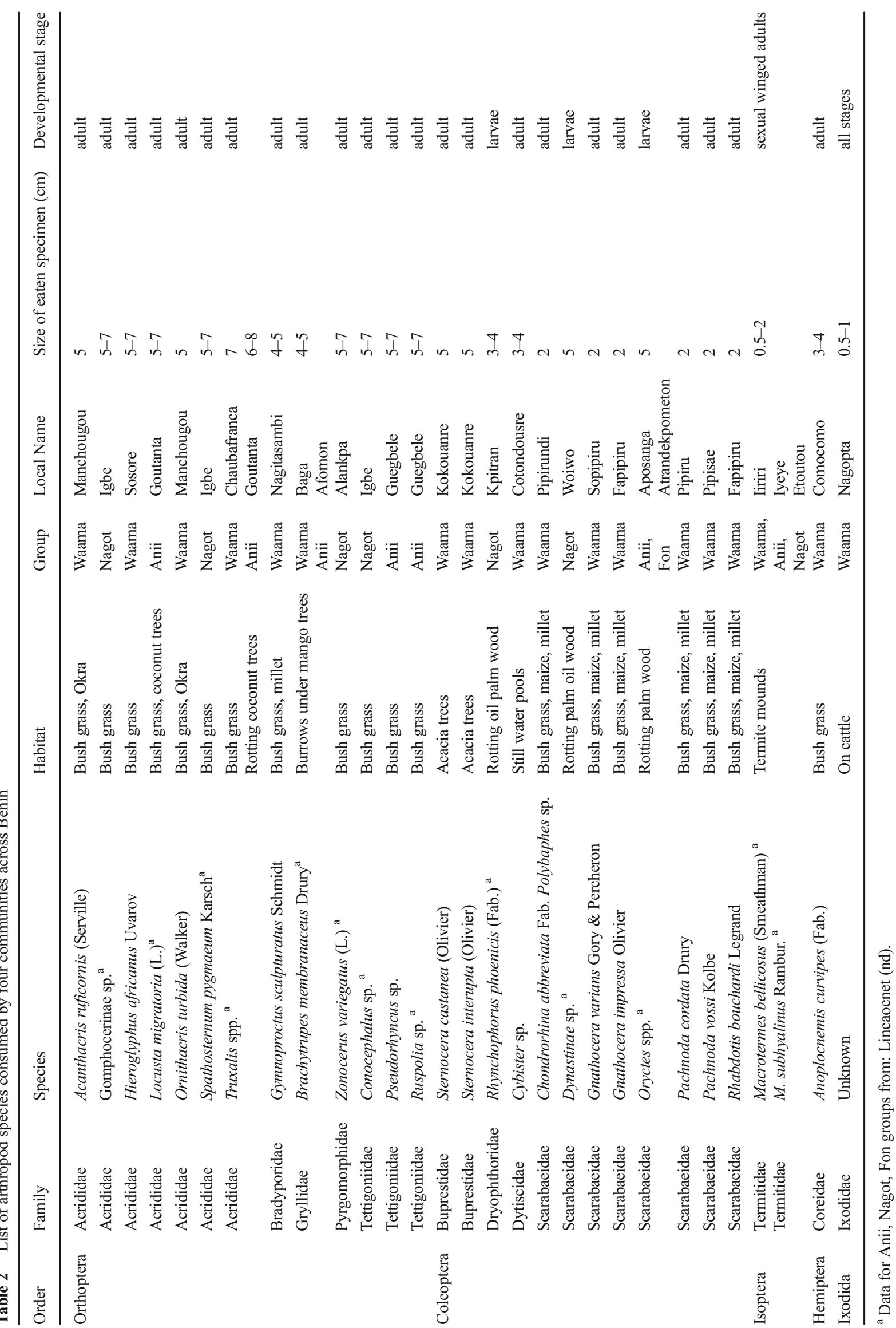

